\title{
How I changed my practice in the last five years and what is likely to change in the next five years
}

The fast development of our field in the last decades has had significant impact on the way we practice our profession. This year my editorials will focus on the impact of these developments on my own daily practice.

When I started in otorhinolaryngology functional endoscopic sinus surgery was the new kid on the block ${ }^{(1,2)}$. We learned to operate as functional as possible. The primary goal of FESS was to restore normal ventilation and remove irreversibly changed mucosa. The concept was that by restoring proper ventilation the sinus would heal itself. In the past decades, we have more and more discovered that CRS and especially CRS with nasal polyps is a mucosal disease that needs intensive medical treatment if necessary combined with ESS ${ }^{(3,4)}$. The concept of FESS has moved from improving ventilation to opening up sinus for local medical treatment ${ }^{(5)}$. Local medical treatment has been shown to be more effective when it is able to enter the sinus (3). Although we do not have all data available yet, rinsing with saline in which local corticosteroids have been dissolved seems to be more effective than using nasal drops and certainly more effective than nasal spray. In this issue of the Journal, Wofford et al. show in a 3D model that FESS, particularly with larger antrostomies, improves topical drug delivery, spray as well as nebulized medication and that certain particle sizes improve this delivery (6). We do not have data at the moment showing whether nebulization is equal or better than rinsing with dissolved nasal corticosteroids. These studies should be done in the near future. For the moment the available data suggest to make large antrostomies and try with nebulization or rinsing to get the drug in the sinus proper.

At the moment we do not have data showing that surgery is better than medical treatment in terms of patient-reported symptom scores and quality of life measurements ${ }^{(7)}$. The concept of CRS being a mucosal disease that needs local treatment implies the combination of surgery and medical treatment ${ }^{(3)}$. An important question, however, is when to operate ${ }^{(8-10)}$. Usually shared decision making between patients and otorhinolaryngologists decides the moment that it has been enough and surgery is needed. Rudmik and colleagues showed that after this shared decision making the choice for more extensive medical treatment was less favourable than FESS ${ }^{(10)}$ and suggest to use SNOT-22 to help in the decision ${ }^{(9)}$. Although these are very relevant data, we need a proper randomized trial between intensified medical treatment and ESS to fully understand the role of surgery in the treatment. That study is performed in the Netherlands at the moment and I hope to be able to report the results in two years.

In this issue of our journal, Claire Hopkins and colleagues show within the famous UK National Comparative Audit of Surgery for Nasal Polyposis and Chronic Rhinosinusitis ${ }^{(11,12)}$ that patients treated surgically early in the history of the disease (i.e., within 12 month of first diagnosis) experienced significantly greater symptomatic benefits from the surgical intervention than patients with longer CRS medical histories ${ }^{(13)}$. Moreover, the same group shows in this issue that these data can be broadened to the UK population and that delayed surgical intervention for CRS is associated with greater post-operative healthcare needs than ESS within 12 months of first CRS diagnosis ${ }^{(14)}$. Especially patients with asthma and/or allergies were shown to be more likely to experience delayed surgical intervention versus other patients. This is worrying, because this group may potentially benefit more from surgical intervention if medical treatment has failed, when compared with non-asthmatic patients ${ }^{(15,16)}$. These data point to much earlier intervention than usually done. In the UK cohort, $11 \%$ is operated within one year and almost $40 \%$ more than 5 years after onset of the CRS symptoms $(13,14)$. These data definitely stimulate me to operate earlier. Ideally, we would like to have data from a prospective trial further proving the data but this will be very costly and maybe impossible to achieve.

Also in this journal, a very relevant and interesting study of Bohman and colleagues clearly points to heredity as an important factor for development of nasal polyps ${ }^{(17)}$. Although a number of studies showed a higher prevalence of nasal polyps in diseases that clearly have a genetic cause like cystic fibrosis or Peutz-Jeghers syndrome in general polyps only gene polymorphism have been proven ${ }^{(18-21)}$. Now it has been shown that nasal polyps have a 5 times higher prevalence in family members of polyp patients. This knowledge suggests we have to warn our patients that their families are more liable to have nasal polyps too. Also, in this issue, Vandenhende-Szymanski and colleagues show that olfactory cleft opacification and CT scan score can predict olfaction improvement after ESS in CRSwNP (22). Although it has been shown before that olfactory function of patients with a high degree of disease in CT scan improved 
more than that of patients with less opacification on CT scan (23), now it is shown that the opacification of the olfactory cleft is a predictive factor. Finally the use of quality of life questionnaires is now common practice in our practice ${ }^{(24-27)}$. It saves a lot of time, and over time improvements, detoriations, exacerbations and treatment effects can easily be measured and in this way improve the quality of care. Now in this issue, Bulut and colleagues who last year developed and validated the Functional Rhinoplasty Outcome Inventory 17 (FROI-17) ${ }^{(28)}$, show that FROI-17 scales correlate significantly with general quality of life measured by SF-36 and showed significant improvement of the disease-specific quality of life after septorhinoplasty ${ }^{(29)}$. As a result, in the measurement of our quality of care in septorhino- plasty we can easily use QoL questionnaires like the FROI-17 to measure benefit of rhinoplasty ${ }^{(30,31)}$.

To conclude: we learned the way we have to think about CRS, a lot about the most effective surgery, getting local therapy where it has to work and how to use outcome measurements in our daily practice. I am curious to see what the fast evolving rhinological field will bring us in the coming year.

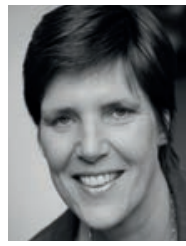

Wytske J. Fokkens, Editor-in Chief

Amsterdam, the Netherlands

\section{References}

1. Stammberger H. Endoscopic endonasal surgery--concepts in treatment of recurring rhinosinusitis. Part II. Surgical technique. Otolaryngol Head Neck Surg. 1986; 94: 147156.

2. Stammberger $\mathrm{H}$, Posawetz W. Functional endoscopic sinus surgery. Concept, indications and results of the Messerklinger technique. Eur Arch Otorhinolaryngol. 1990; 247: 63-76.

3. Fokkens WJ, Lund VJ, Mullol J, et al. European Position Paper on Rhinosinusitis and Nasal Polyps 2012. Rhinology Supplement. 2012 (23): 1-298.

4. Snidvongs K, Dalgorf D, Kalish L, Sacks R, Pratt E, Harvey RJ. Modified Lund Mackay Postoperative Endoscopy Score for defining inflammatory burden in chronic rhinosinusitis. Rhinology. 2014; 52: 53-59.

5. Harvey RJ, Schlosser RJ. Local drug delivery. Otolaryngol Clin North Am. 2009; 42: 829845.

6. Wofford MR, Kimbell JS, Frank-Ito DO, A computational study of functional endoscopic sinus surgery and maxillary sinus drug delivery. Rhinology. 2015; 53: 41-48

7. Rimmer J, Fokkens W, Chong LY, Hopkins C. Surgical versus medical interventions for chronic rhinosinusitis with nasal polyps. Cochrane Database Syst Rev. 2014;12:CD006991.

8. Rizzi MD, Kazahaya K. Pediatric chronic rhinosinusitis: when should we operate? Curr Opin Otolaryngol Head Neck Surg. 2014; 22: 27-33.

9. Rudmik L, Soler ZM, Mace JC, DeConde AS, Schlosser RJ, Smith TL. Using preoperative SNOT-22 score to inform patient decision for Endoscopic sinus surgery. Laryngoscope. 2014. doi: 10.1002/ lary.25108. [Epub ahead of print]

10. Rudmik L, Soler ZM, Mace JC, Schlosser RJ, Smith TL. Economic evaluation of endoscopic sinus surgery versus continued medical therapy for refractory chronic rhinosinusitis. Laryngoscope. 2015; 125: 25-32.

11. Hopkins C, Browne JP, Slack R, et al. The national comparative audit of surgery for nasal polyposis and chronic rhinosinusitis. Clin Otolaryngol. 2006; 31: 390-398.

12. Hopkins C, Slack R, Lund V, Brown P, Copley L, Browne J. Long-term outcomes from the English national comparative audit of surgery for nasal polyposis and chronic rhinosinusitis. Laryngoscope. 2009; 119: 24592465.

13. Hopkins C, Rimmer J, Lund VJ. Does time to endoscopic sinus surgery impact outcomes in chronic rhinosinusitis? Prospective findings from the national comparative audit of surgery for nasal polyposis and chronic rhinosinusitis. Rhinology. 2015; 53: 10-17.

14. Hopkins C, Andrews P, Holy CE. Does time to endoscopic sinus surgery impact outcomes in chronic rhinosinusitis? Retrospective analysis using the UK clinical practice research data. Rhinology. 2015; 53: 18-24

15. Zhang Z, Adappa ND, Doghramji LJ, et al Quality of life improvement from sinus surgery in chronic rhinosinusitis patients with asthma and nasal polyps. Int Forum Allergy Rhinol. 2014; 4: 885-892.

16. Vashishta R, Soler ZM, Nguyen SA, Schlosser RJ. A systematic review and meta-analysis of asthma outcomes following endoscopic sinus surgery for chronic rhinosinusitis. Int Forum Allergy Rhinol. 2013; 3: 788-794.

17. A. Bohman, M. Oscarsson, K. Holmberg, et al. Heredity of nasal polyps. Rhinology. 2015; 53: 25-28

18. Kosugi EM, de Camargo-Kosugi CM, Hirai ER, et al. Interleukin-6-174 G/C promoter gene polymorphism in nasal polyposis and asthma. Rhinology. 2013; 51: 70-76.

19. Buysschaert ID, Grulois V, Eloy P, et al Genetic evidence for a role of IL33 in nasal polyposis. Allergy. 2010; 65: 616-622.

20. de Leng WW, Westerman AM, Weterman MA, et al. Nasal polyposis in Peutz-Jeghers syndrome: a distinct histopathological and molecular genetic entity. J Clin Pathol. 2007; 60: 392-396.

21. Berkhout MC, van Rooden CJ, Rijntjes E, Fokkens WJ, el Bouazzaoui LH, Heijerman
HG. Sinonasal manifestations of cystic fibrosis: a correlation between genotype and phenotype? J Cyst Fibros. 2014;13: 442-448.

22. C. Vandenhende-Szymanski, B. Hochet, D. Chevalier, G. Mortuaire. Olfactory cleft opacity and CT score are predictive factors of smell recovery after surgery in nasal polyposis. Rhinology. 2015; 53: 29-34.

23. Minwegen F, Thomas JP, Bernal-Sprekelsen M, Dazert S, Minovi A. Predictive value of disease severity on self-reported rating and quantitative measures of olfactory function outcomes after primary endoscopic sinus surgery. A prospective study. Rhinology. 2014; 52: 437-443.

24. Taylor RJ, Miller JD, Rose AS, et al. Comprehensive quality of life outcomes for pediatric patients undergoing endoscopic sinus surgery. Rhinology. 2014; 52: 327-333.

25. Sami AS, Scadding GK. Rhinosinusitis in secondary school children-part 2: main project analysis of MSNOT-20 Young Persons Questionnaire (MSYPQ). Rhinology. 2014; 52: 225-230.

26. Penttila E, Smirnov G, Seppa J, Tuomilehto $H$, Kokki $H$. Validation of a symptom-score questionnaire and long- term results of endoscopic dacryocystorhinostomy. Rhinology. 2014; 52: 84-89.

27. Fokkens WJ. Patient-centered treatment goals. Rhinology. 2013; 51: 193-194.

28. Bulut C, Wallner F, Plinkert PK, Baumann I. Development and validation of the Functional Rhinoplasty Outcome Inventory 17 (FROI-17). Rhinology. 2014; 52: 315-319.

29. Bulut OC, Wallner F, Plinkert PK, Prochnow S, Kuhnt C, Baumann I. Quality of life after septorhinoplasty measured with the Functional Rhinoplasty Outcome Inventory 17 (FROI17). Rhinology. 2015; 53: 54-58

30. Takhar AS, Stephens J, Randhawa PS, Poirrier AL, Andrews P. Validation of the sino-nasal outcome test-23 in septorhinoplasty surgery. Rhinology. 2014; 52: 320-326.

31. Mendis D, Cheang PP, Glossop LP. Audit: patient reported outcomes of extracorporeal septorhinoplasty. Rhinology. 2013; 51: 88-92. 